\title{
N. TSANKOV
}

\section{Development of the modeling competence of students in the pedagogical majors in the conditions of a simulation training in computer-based distance learning}

The problem and the aim of the study. The increased use of digital technologies in higher education has lately been accelerated by the COVID-19 pandemic, thus creating a number of challenges related to the implementation of distance e-learning. The duration of the epidemic situation and the limitations related to the organization of in-person education reveal the simulation training as the main opportunity for the implementation of any practical training of the students in the methodological disciplines in their university preparation as future teachers. The aim of the study is to survey the possibilities of developing the modeling competence of students concerning the simulation of practical training in computer-based distance learning.

Research methods. Within the framework of the research, which is oriented at establishing the levels of structure defining competencies (the reflective multisensory competency; the creative competency; the symbolic competency of sign and symbol nature) were measured systematically through goal-oriented observation during practice seminars in the disciplines taught to students. Since both disciplines are practically oriented and suggest the instruction of teaching methods, they entail the design of didactic situations in pre-school and of lessons in primary school education, which facilitates the registering of the levels of structure defining competences, including the competence for cognitive modelling, preeminently formed in the conditions of simulative distance education in electronic environment. The subjects participating in the research are 158 Bachelor's students trained in the professional field Education Science.

Results. A low level of the skills for the application of cognitive modelling in the activities students conduct in relation to the design of pedagogical situation and lessons as an element in their practical experience and preparation in the realization of such situations in rela school conditions. The pilot study diagnoses a low level of student achievements in over $65 \%$ of the subjects as regards the academic disciplines the study concerns in terms of basic modelling skills. By contrast, in the course of the simulative education a growth of $45 \%$ has been established in the concluding study. The intersections and correlations between the level of development of the specific competences and the simulative education have also been established. Statistically verifiable differences $(p=<0.05)$ were established between the pilot and the concluding studies in view of the reflective and creative competency. The symbolizing competency, however, requires further efforts.

Conclusion. The results draw the attention to the necessity to look for opportunities to guarantee the creation of the models, in the context of simulative education, with three basic emphases: state (value, role and function in the specific context, phase of development of the pedagogical situation and/or lesson), structure (position of the model in relation to the other models/objects and of its own components - the components of the pedagogical situations and lesson projects) and evolution (opportunities for the design of pedagogical situations and/or lessons after reflection based on simulations).

Keywords: modeling competence, simulation training in an electronic environment from a distance, students future teachers, practical education, research perspectives

\section{For Reference:}

Tsankov, N. (2021). Development of the modeling competence of students in the pedagogical majors in the conditions of a simulation training in computer-based distance learning. Perspektivy nauki i obrazovania - Perspectives of Science and Education, 53 (5), 238-246. doi: 10.32744/

pse.2021.5.16 


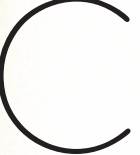

omputer-based distance learning creates various opportunities for the construction of simulation models of pedagogical situations and lessons within the training in the methodological disciplines in the preparation of students - future teachers. In the context of the goals for developing the cognitive modeling competence of students from the pedagogical majors, there appears an environment suitable for applying didactic strategies for metaphorization, symbolization, analogization, association, visualization and synergization in combining cognitive modeling and simulation of pedagogical situations and lessons in electronic remote environment while using the potential of information and communication technologies and working in a digital environment.

\section{Literature review}

Despite the existing studies on the role of modeling as a method for scientific and educational knowledge, which clearly outline its importance, the question of students' ability to apply modeling in their cognitive activity and thus to develop their competence in cognitive modeling, remains open.

Within the scope of the present study and based on previous research and conclusions about the competence as a construct and about modeling as a cognitive activity, the competence in cognitive modeling should be considered as an integral personal characteristic, comprised of a system of knowledge, skills (integrated in a specific context) - competencies and attitude [18].

The competence in cognitive modeling must be motivating and transversal (transferable), must have priority of intention (style, strategy), and must not be reduced to a mere instrument of adaptation and personal skill that gives meaning to different cognitive situations. In order for this to be the case, the competence must include: (1) in terms of content - knowledge of: models and modeling; modeling of genus-species relationships; modeling of causal relationships and relations; modeling of dependencies and content abstractions; modeling in thought experiments; modeling of the processes and phenomena from the objective reality for the purpose of their explanation; (2) in active aspect - skills for: research of the objects and revealing their essential features; systematization and generalization of essential initial information about the studied object in mental, verbal, visual or other form; creating models; selecting models (selection) of the most suitable for the respective situation); practical and/or theoretical verification of the models; encoding, decoding and recoding of information into and through models; transfer of the knowledge obtained for the model, as such knowledge about the studied object; (3) in personal aspect - the attitude of students to the educational cognitive modeling: as an activity and to the results of this activity as a strategy for effective learning.

The set of skills included in the content of the competence in educational cognitive modeling with a certain degree of generalization are defined and summarized to skills for: (1) research of the objects and revealing their essential features; (2) systematization and summarization of essential source information; (3) creating/developing models; (4) selection of models (selection of the most appropriate one for the respective situation); (5) practical and/or theoretical verification of the models; (6) encoding, decoding and recoding 
information into and through models; (7) transfer of the knowledge obtained about the model, as knowledge about the studied object.

These skills, in combination with the relevant knowledge, are summarized in three main competencies: reflective - multisensory, creative - visual-affective and symbolic - signsymbol, the detailed content of which is presented in Table 1.

Table 1

Composite competencies that build the competence for cognitive modeling

\begin{tabular}{|l|l|}
\hline \multicolumn{1}{|c|}{ Competency } & \multicolumn{1}{c|}{ Description } \\
\hline $\begin{array}{l}\text { Reflective - multisensory } \\
\text { competency }\end{array}$ & $\begin{array}{l}\text { Directly related to the knowledge and skills for multisensory search and detection of } \\
\text { signals and their establishment as essential characteristics, features, properties and } \\
\text { specifics of the studied objects, processes and phenomena. The generalization and } \\
\text { systematization of this array of information leads to its transformation and coding into } \\
\text { mental images and ideas, the subsequent interpretation and use of which leads to the } \\
\text { recoding and integration of information in and through different models. }\end{array}$ \\
\hline Creative competency & $\begin{array}{l}\text { It is connected with the interpretation of the obtained array of information by: } \\
\text { abstraction from specific multisensory information by summarizing, systematizing } \\
\text { and structuring; visual representation of multisensory information transformed } \\
\text { through inductive, deductive and translational inferences, comparisons and other } \\
\text { logical operations, use, interpretation and development of classifications, conceptual } \\
\text { and other schemes, as well as tables, diagrams, graphs and other models; indirect } \\
\text { reproduction of multisensory perceptions of real objects and phenomena by } \\
\text { developing different models; deriving problems and searching for their solution } \\
\text { through algorithmic and non-algorithmic prescriptions. }\end{array}$ \\
\hline $\begin{array}{l}\text { Symbolic - sign-symbol } \\
\text { competency }\end{array}$ & $\begin{array}{l}\text { Presentation of the developed educational product - model. Although various material } \\
\text { products are created within the framework of the training, in the context of the } \\
\text { research the educational product is seen as an intellectual one. }\end{array}$ \\
\hline
\end{tabular}

Historically, the design of simulation models has been of interest to a myriad of researchers [11] especially in the context of the booming development of digital technologies [5].

There is a number of studies which systematically address the evolution of the theory and practice of simulation training [16] as well as their impact on its design and implementation in a technology-enriched environment [8]. There is also research interest in the field of simulation training in the course of preparing university students to become future teachers [2].

Other studies focus on the role of simulation in the training of prospective teachers in different subject areas, such as Natural Sciences [4], as well as on the formation of the professional identity of teachers [3]. Certain systematic research studies are oriented to the issues of the effectiveness of simulative education in the context of training teachers at different levels of school education [16].

Two types of simulation models are used in education and in the training of prospective students. In the real (physical) simulation model one student acts as a teacher and the rest - as pupils or learners with the instructor acting as monitor and giving feedback later. Its implementation includes: a natural classroom environment; a low affective filter and active participation in the session; lesson delivery in the classroom implying all the requisite skills of teaching; individualization of the teaching process; feedback from the students; improvement on the weak points as recognized through students' feedback. The virtual model, in turn, uses media and IT to provide a simulated classroom environment. The task of the prospective teacher is to recognize the learning difficulties of students and guide them to improvement. What is important about such models is that the simulated environment can be created at any time and is extremely cost-effective [16]. 
Another research perspective is the development of reasoning through 3D-modelling [8], which is closely linked with the simulative education of prospective pedagogical specialists in the context of the acquisition of skills that are required on the labour market. This is also linked with the opportunities for its personalization through "a personal educational trajectory" or "a personal educational route" [6].

When conducting simulation training within the practical courses in the methodical disciplines, the simulations involve putting of the model into action. Modeling and simulation represent two aspects (or two phases) of an activity that people perform spontaneously, without realizing it, and are often performed only mentally and are absolutely necessary for adequate and effective behavior in specific situations [15]. For students, the design of pedagogical situations and lessons within their practical courses in methodological subjects is related to modeling - as constructing a general and indirect idea of translating these situations and lessons into reality (students already have models based on observations of pedagogical specialists) and imagine them (simulate) and express them (put them into action).

These cognitive models developed in the course of training future teachers should be represented in the most appropriate way by challenging students to visualize and implement the imaginary simulations. Thus, according to Y. Merdzhanova, modeling and simulation will fully perform their didactic functions, namely: (1) research function - in the course of modeling and simulation, pedagogical situations and lessons are studied from different angles for different purposes. They can be modified and enriched with additional effects, can be evaluated, and the most appropriate ones can be selected. The application of their constructive aspect can be analyzed in real pedagogical conditions; (2) interpretation function, as providing an opportunity for the continuous upgrading of the planning of pedagogical situations and lessons in their most pragmatic implementation; (3) training and development function - models and simulations allow cognitive and practical activity in which mistakes and consequences will not be fatal as in reality, allow action and behavior in complex situations, feeling and perception of the whole picture, not only separate aspects and elements [15].

Simulation-based learning consists of a series of simulations that allow the procedural development of initial experience without the consequences of factual and methodological errors. The leading approach in the pedagogical simulations of the simulation-based learning is research-based. This is a practical training in which a pedagogically holistic environment is imitated or constructed. With its contextuality it helps the students develop adequate, flexible and adaptive social-pedagogical skills. When planning pedagogical simulations, a systematic approach is applied, ranking simulations with repeating elements, simulations with different levels of difficulty, integrative simulations, hierarchically developing simulations [12].

Thus, the limitations imposed by the worldwide pandemic and the ongoing work in computer-based distance learning paves the way for the optimization of technological options for the development of competence for cognitive modeling of students - future teachers - in stimulating training, where the construction of simulation models of pedagogical situations and lessons develops methodological models both in terms of their value, role and functions in the specific methodological context, their position in relation to other (other students') models - projects and/or own components of the project, as well as in terms of evolutionary perspective and development of the designed methodological variants. 
The empirical research was conducted between September 2020 - June 2021 with a contingent of 158 students doing a Bachelor's degree in professional field Pedagogy (future pre-primary and primary school teachers) of the Faculty of Education at the Trakia University - Stara Zagora.

The research aims to determine which of the structure-determining competencies (reflective - multisensory competency; creative competency; symbolic - sign-symbolic competency), forming the competence for cognitive modeling, primarily develops in the conditions of simulation learning in an electronic environment in the context of distance education. On the other side, particular emphasis is laid on a variety of opportunities for the competence improvement with a view to future professional development.

As a part of the research, analysis of the current situation has been conducted aiming to estimate the level of application of educational-cognitive modeling in the design of methodological variants of pedagogical situations and lessons at the beginning of the period of computer-based distance learning in the selected methodological disciplines (Pedagogy of constructive-technological and household activities and Theory and methodology of technical and technological training in grades 1-4).

\section{Research results and Discussion}

The established low level in over $65 \%$ of the students' achievements within the two academic disciplines in which subject field the research is conducted is in terms of skills for: revealing the essential features in specific methodological variants of pedagogical situations and lessons; coding, decoding and recoding of information from different models of pedagogical situations and lessons as well as in the transfer of knowledge obtained from one model of pedagogical situations and/or lesson onto the plan for another situation or lesson. The results of the analysis of the structure-determining competences included in the competence for cognitive modeling are summarized in Table 2.

The general conclusion is that two thirds of the students - future children's and primary teachers - do not have the skills to apply the educational-cognitive modeling in their design of pedagogical situations and lessons, as an element of their practical preparation in both kindergarten and primary school. This, in turn, required them in the course of the simulation training to pay special attention to the knowledge of models and modeling and skills to apply it, as well as to increase interest in modeling and motivating students to consciously and systematically include it in the cognitive process in order to build an active attitude to this activity and its results and to apply it in real pedagogical practice.

The simulations in the training have the following main characteristics: they are related to realistic functions; they are safe and competently developing; they are structured; they are active/dynamic, i.e students can break them down into components and further develop them.

Historically, a number of challenges have been identified, mainly the use of various technological solutions that create conditions for full training through simulations, initially in a very narrow range of areas and suebsequently in a number of areas requiring professional skills acquired in simulation training [7]. 
Table 2

Distribution of the results of the analysis of the current situation

\begin{tabular}{|c|c|c|c|}
\hline \multirow{3}{*}{\multicolumn{2}{|c|}{$\begin{array}{l}\text { Competency/ skills for } \\
\text { modelling }\end{array}$}} & \multicolumn{2}{|c|}{ Courses } \\
\hline & & \multirow{2}{*}{$\begin{array}{c}\text { Pedagogy of constructive-technological } \\
\text { and household activities } \\
\% \\
\end{array}$} & \multirow{2}{*}{$\begin{array}{c}\text { Theory and methodology of technical and } \\
\text { technological training in grades } 1-4 \\
\%\end{array}$} \\
\hline & & & \\
\hline \multicolumn{4}{|c|}{ Reflective - multisensory competency } \\
\hline \multirow[t]{3}{*}{ level } & Low level & 65.63 & 67.26 \\
\hline & Average level & 24.65 & 25.65 \\
\hline & High level & 9.72 & 7.09 \\
\hline \multicolumn{4}{|c|}{ Creative competency } \\
\hline \multirow[t]{3}{*}{ level } & Low level & 74.89 & 68.25 \\
\hline & Average level & 22.32 & 26.65 \\
\hline & High level & 2.79 & 5.1 \\
\hline \multicolumn{4}{|c|}{ Symbolic - sign-symbol competency } \\
\hline \multirow[t]{3}{*}{ level } & Low level & 85.63 & 83.65 \\
\hline & Average level & 12.33 & 12.65 \\
\hline & High level & 2.04 & 3.7 \\
\hline
\end{tabular}

In the course of the simulation training, in which the main component is the pedagogical simulation, the leading assumptions are those made by R. Neminska for the interdisciplinary pedagogical simulation, namely: (1) the trainee is encouraged to apply different strategies, to make plans and predictions, and to think ahead; (2) cooperation, forecasting and full goal-setting are encouraged by expanding the boundaries of designing pedagogical situations and lessons; (3) decision-making and reflection on the activity are encouraged, as well as the assessment of the consequences of the decisions taken [12].

In the course of the simulation training a technology of construction of simulation models is applied, taking into account the development of the models in three areas - state (value, role and function in the specific context, phase of development of the pedagogical situation and/or lesson), structure (position of the model in relation to the other models/objects and of its own components - the components of the pedagogical situations and lesson projects) and evolution (opportunities for development of pedagogical situations and/or lessons after reflection based on simulations) [14]. In the course of the training opportunities were sought to predict the limits of variations (of the state, of the structure, of the evolution), the factors of variations (past experience / precedence, synchronizations, causal variations) and the rules of variations (sequences in the natural development of state (intensity, amplitude, frequency), structure and evolution). The created simulation models are assessed in terms of the selected educational content, goal setting, task-activity development of the pedagogical situation and/or lesson; evaluation mechanisms and possible methodological reflections. The simulation training in computer-based distance learning is seen as a possible intermediate testing of methodological variants of pedagogical situations and/or lessons designed by the students, an opportunity for their improvement and formation of skills for continuous professional self-evaluation.

The application of simulations in the course of training of students - future preprimary and/or primary teachers in computer-based distance education in the disciplines 
"Pedagogy of constructive-technological and household activities" and "Theory and methodology of technical and technological training in grades 1.-4" as well as the potential of information and communication technologies and work in a digital environment in the design of pedagogical situations and/or lessons successfully integrate the rational and the affective and develop modeling skills, underlying the core of the structure-determining competencies of cognitive modeling competence.

The final study found a significant increase (by over 45\%) in favor of skills for multisensory search and detection of signals and their fixation as essential characteristics, traits, properties and signs of the studied pedagogical situations and/or lessons, summarizing and systematizing information, its transformation and visualization/coding, its further interpretation and its recoding in the design of new pedagogical situations and lessons (reflective - multisensory competence). The most significant increase of $52 \%$ was found in terms of skills that constitute creative competence: abstraction from specific multisensory information through aggregation, systematization and structuring; visual representation of multisensory information transformed through inductive, deductive and translational inferences, comparisons and other logical operations, use, interpretation and development of classification, conceptual and other schemes; indirect reproduction of multisensory perceptions of real objects and phenomena by developing different models; deriving problems and searching for their solution through algorithmic and non-algorithmic prescriptions in the course of designing subsequent / new pedagogical situations and/or lessons.

The result is still unsatisfactory in terms of symbolic - sign-symbol competence, as the established increase is $23 \%$ at the end of the study. This draws attention to the search and use of software applications developing visualization skills (symbol-sign), guaranteeing further opportunities for discovery and creation of concepts, construction of mental images and their representation in development through various heuristic schemes, mind maps, conceptual diagrams, etc., as a basis for a fuller understanding of the pedagogical situations and methodological variants of lessons, their understanding, systematization, comparison, abstraction, modification.

The statistical interpretation of the data in relation to the individual competencies is summarized and will be analyzed in terms of the objectives of the empirical study using indicators according to established procedures.

In the application of the already analyzed technological variant within the simulation training in computer-based distance education for the development of the competence for cognitive modeling of the formed group of students from professional field Pedagogy (Bachelor's Degree) for the comparison of the results on the structure-determining competencies of the competence for cognitive modeling the following statistical procedures are used: Wilcoxon's Signed - Rank Test (Wilcoxon) for comparison of two correlated (connected) samples (groups). The results of its application show the associated significance level given in the Asymp line. Sig. (2-tailed), in relation to the "Reflective - multisensory competency" - $p=0.45<0.05$, in relation to the indicator "Creating competency" - $p=0.065<0.05$ and in relation to the indicator "Symbolic - sign-symbol competency" $-p=0.02>0.05$. In the first two competencies, it is reasonable to conclude that the difference between the two assessments is statistically significant, which is the basis for accepting the alternative hypothesis, which states that the applied technology for simulation learning computer-based distance education supports the development of two out of three structure-determining competencies of cognitive modeling of students 
and that additional conditions are necessary for the development of the symbolic - signsymbol - competency.

In the course of processing the results, a connection emerges between the factors of variations (past experience/precedence, synchronizations, causal variations) and the creative competency, as a segment of the competence for cognitive modeling. For this purpose, correlation analysis was used - a statistical method for studying the relationship between variables in order to reveal the strength of the dependence, using the Pearson coefficient for simple linear correlation. In this case, the Pearson correlation coefficient is $r=0.684$, which shows a significant strength (degree) of the relationship between the degree of variation of factors and the development of the capacity to eliminate specific multisensory information by summarizing, systematizing and structuring; visual representation of multisensory information transformed through inductive, deductive and translational inferences, comparisons and other logical operations, use, interpretation and development of classification, conceptual and other schemes; indirect reproduction of multisensory perceptions of real objects and phenomena by developing different models; deriving problems and searching for their solution through algorithmic and non-algorithmic prescriptions in the course of designing subsequent/new pedagogical situations and/or lessons (constructs of the creative competency). There are grounds to conclude that when a certain level of development of skills from the creative competency is reached, a full assessment and reflection on the variability of the factors in the course of the simulation training will be provided.

Conclusion

The competence for cognitive modeling, developed in the conditions of simulation training in computer-based distance education, should be seen as: "living" (non-statically framed), having a life path on different levels, which is embossed (fluidly dynamicresistant spiral) and has important points (base segments / spheres); there are centers (such as transgressive zones with dynamic resilience) of metamorphoses, as starting points and transitions to other levels (emerging spheres), as well as critical points seen as potential new spheres. In the border areas of the deep structure, numerous principles are synergized as sources, not as first/primary points and numerous possible outcomes as extensions (aspects of transgressiveness - shifting the borders), and not as end points (according to Y. Rasheva-Merdzhanova) [14].

Thus, the competence for cognitive modeling developed in the conditions of simulation training in computer-based learning will have the potential to be employed in practical pedagogical situations by ensuring its self-awareness, self-regulation and selfdevelopment.

Funding

The research is an implementation of Project № 2 / PF Modeling of simulation-based learning environments and studying its pedagogical effectiveness in academic training, funded by the Trakia University - Stara Zagora. 


\section{REFERENCES}

1. Bekmanova, G., Ongarbayev, Y., Somzhurek, B. et al. Personalized training model for organizing blended and lifelong distance learning courses and its effectiveness in Higher Education. J Comput High Educ, 2021. DOI: 10.1007/ s12528-021-09282-2

2. Brown, A. H. Simulated classrooms and artificial students: The potential effects of new technologies on teacher education. Journal of Research on Computing in Education, 1999, vol. 32, no. 2, pp. 307-318. DOI: 10.1080/08886504.1999.10782281

3. Carrington, L., Kervin, L., Ferry, B. Enhancing the development of pre-service teacher professional identity via an online classroom simulation. Journal of Technology and Teacher Education, 2011, vol. 19, no. 3, pp. 351-368.

4. Dotger, S., Dotger, B. H., Tillotson, J. Examining how preservice science teachers navigate simulated parent-teacher conversations on evolution and intelligent design. Science Teacher Education, 2009, vol. 94, pp. 552-570. DOI: $10.1002 /$ sce. 20375

5. Fishwick, P. A. Simulation Model Design and Execution: Building Digital Worlds, Prentice-Hall.1995.

6. Jasmine P., Felicia J. A Comparative Analysis of Student Performance in an Online vs. Face-to-Face Environmental Science Course From 2009 to 2016. Frontiers in Computer Science, 2019, vol. 1, p. 7. DOI: 10.3389/fcomp.2019.

7. Kincaid, J. P., Westerlund, K. K. Simulation in Education and Training. In Proceedings of the Winter Simulation Conference, edited by M. D. Rossetti, R. R. Hill, B. Johansson, A. Dunkin, and R. G. Ingalls, Piscataway, New Jersey: Institute of Electrical and Electronic Engineers, 2009, pp. 273-280.

8. Kiryakova-Dineva T., Levunlieva M., Kyurova V. Iphras as an E-learning platform for idiomatic competence. Electronic Journal of e-Learning, 2017, vol. 15, issue 2, pp. 137-143.

9. Larson, R.C., Murray, M.E. Distance Learning as a Tool for Poverty Reduction and Economic Development: A Focus on China and Mexico. J Sci Educ Technol, 2008, vol. 17, pp. 175-196. DOI: 10.1007/s10956-007-9059-1

10. Masharova, T. V., Bushmeleva, N. A., Perevozchikova, M. S., \& Khlobystova, I. Yu. Using 3D technologies to developing innovative thinking. Perspektivy nauki i obrazovania - Perspectives of Science and Education, 2020, vol. 45, no. 3, pp. 426-440. DOI: 10.32744/pse.2020.3.31

11. Naylor, T. H., Balintfy, J. L., Burdick, D. S., Chu, K. Computer Simulation Techniques, John Wiley, 1966.

12. Neminska, R. Simulation based pedagogical training. Kota Publishers, Stara Zagora, 2015 (In Bulgarian).

13. Novgorodtseva, A. N., Tomyuk, O. N., Dyachkova, M. A., \& Piankova, M. P. Online marketplace: student consumer strategies. Economic consultant, 2020, vol. 32 (4), pp. 41-53. DOI: 10.46224/ecoc.2020.4.5

14. Pashuk, N. R., Bulgakova, M. A. The role of environmental competence of the teacher in professional activities. Economic consultant [The State Counsellor], 2019, vol. 26 (2), pp. 105-113.

15. Rasheva-Merdzhanova, Y. Basic methodological approaches for transversal competences. Sofia University Publishing House, Sofia, 2014 (In Bulgarian).

16. Rasheva-Merdzhanova, Y. Multisensory principle in training and real life. Sofia University Publishing House, Sofia, 2005 (In Bulgarian).

17. Ruben, B. D. Simulations, games, and experience-based learning: The quest for a new paradigm for teaching and learning. Simulation \& Gaming, 1999, vol. 30, no. 4, pp. 498-505. DOI: 10.1177/104687819903000409

18. Sharma, M. Simulation Models for Teacher Training: Perspectives and Prospects. Journal of Education and Practice, 2015, vol. 6, no. 4, pp. 11-14.

19. Tsankov, N. Competence for cognitive modeling. Didactic concretization and development. Avangard Prima Publishers, Sofia, 2013 (In Bulgarian).

20. Turan, S. Simulation-based learning: how can be used to prepare teacher? Educação, Ciência e Cultura, 2015, vol. 20, no. 1, pp. 28-43. DOI: 10.18316/2236-6377.15.2

\section{Information about the author}

Nikolai Tsankov

(Bulgaria, Stara Zagora)

Associate Professor, PhD, Faculty of Education

Trakia University

E-mail: ntsankov@abv.bg

ORCID ID: 0000-0002-3206-8144

Scopus Author ID: 26027356200

ReseacherID: E-3949-2014 